\title{
Do Defense Styles of Ego Relate to Volumes of Orbito-Frontal Cortex in Patients with Obsessive-Compulsive Disorder?
}

\author{
Murad Atmaca ${ }^{1}$, Hanefi Yildirim², Mustafa Koc ${ }^{2}$, Sevda Korkmaz ${ }^{1}$, Sinan Ozler ${ }^{1}$ and Zehra Erenkus ${ }^{3}$ \\ ${ }^{1}$ Departments of Psychiatry and ${ }^{2}$ Radiology, School of Medicine, Firat University, Elazig, Turkey \\ ${ }^{3}$ Department of Biostatistics, School of Medicine, Hacettepe University, Ankara, Turkey
}

Objective Although the importance of orbito-frontal cortex (OFC) is established in the pathogenesis of obsessive compulsive disorder (OCD), no study have evaluated its relation to the traditional psychodynamic perspective. In the present study, we aimed to evaluate the relationship between the defense styles consisting of mature, immature and neurotic defenses and OFC volumes of patients with OCD.

Methods Subjects were selected among those of our previous study, and so eighteen patients with OCD and same number of healthy controls were took into the study. The patients and controls had underwent magnetic resonance imaging (MRI). In addition, the Defense Style Questionnaire- 40 was administered to obtain defense styles of patients and controls.

Results No significant relationship was found between the right OFC volumes of both the patient and control groups and their scores of mature, neurotic, or immature defense mechanisms. As for the left OFC volumes, the only significant relationship for the scores of immature defense mechanism was found in the patient group.

Conclusion The results of the present study indicated that there was no significant relationship between OFC volumes of the patient group and their scores of mature, neurotic, or immature defense mechanisms, except a significant relation with the scores of immature defense mechanisms.

Psychiatry Investig 2011;8:123-129

Key Words MRI, Defense syles, OFC, OCD.

\section{INTRODUCTION}

Obsessive-compulsive disorder (OCD) comprising core symptoms of obsessions and compulsions is a common, chronic, anxiety disorder that can have disabling effects throughout lifetime with a wide range of clinical pictures. Its etiopathogenesis is obscure despite a huge different data coming from genetic, neurobiological, neurochemical and neuroimaging investigations.

Recent brain imaging techniques have revealed that specific circuits are responsible for the pathogenesis of OCD symptoms, ${ }^{1}$ particularly prefrontal-basal ganglia-thalamic-prefrontal circuits. ${ }^{2}$ Structural imaging studies of OCD have sug-

Received: July 6, 2010 Revised: December 29, 2010

Accepted: January 14, 2011 Available online: February 15, 2011

$\triangle$ Correspondence: Murad Atmaca, MD

Department of Psychiatry, School of Medicine, Firat University, Firat Tip Merkezi Psikiyatri Anabilim Dali 23119 Elazig/Turkey

Tel: +90-424-233-3555, Fax: +90-424-238-8096

E-mail: matmaca_p@yahoo.com

(a) This is an Open Access article distributed under the terms of the Creative Commons Attribution Non-Commercial License (http://creativecommons.org/licenses/by$\mathrm{nc} / 3.0$ ) which permits unrestricted non-commercial use, distribution, and reproduction in any medium, provided the original work is properly cited. gested basal ganglia and frontal pathology, ${ }^{2}$ with inconsistent reports of increases, ${ }^{3}$ decreases ${ }^{4,5}$ or no differences. ${ }^{6-12}$

In a recent meta-analysis, Whiteside et al..$^{13}$ reported that meta-analytic results partially supported the conclusions drawn from previous narrative reviews that point to structures in the orbito-frontal cortex (OFC), caudate nucleus, anterior cingulate, and thalamus as the key brain regions in the pathophysiology of OCD. Functional imaging studies found altered activity in basal ganglia and prefrontal areas at rest and during behavioral challenge with feared stimuli in OCD patients. ${ }^{14} \mathrm{In}$ addition to knowledge all above, as mentioned by MacMaster et al., ${ }^{15}$ we should note that a critical brain region in this circuit is the OFC which is structurally the most ventral portion of the prefrontal cortex and have rich connections to the amygdala and dorsomedial thalamus ${ }^{16}$ areas implicated in $\mathrm{OCD}^{17-20}$ and functionally, it plays a role in linking affective value to reinforcing stimuli, sensory processing, and decision-making ${ }^{21}$ and which of all may be affected in OCD. ${ }^{22}$ On the other hand, OFC was probably found as the most important key brain region in our two previous study. ${ }^{23,24}$

According to psychoanalytic theory, obsessions and com- 
pulsions reflect maladaptive responses to unconsciously unresolved conflicts from early periods of psychological development and in Freud's view the patient's mind responded maladaptively to conflicts between unacceptable, unconscious sexual or aggressive id impulses and the demands of conscience and reality. This theory suggests that the ego marshalled certain defense mechanisms such as intellectualization and isolation, undoing to neutralize the offending ideas and impulses and reaction formation to adopt character traits exactly opposite of the feared impulses.

When we take a look at the psychiatric literature, there is dearth in the investigations which evaluate the relationship and interaction between neurobiological and psychoanalytic dimensions of psychiatric disorders. These investigations evaluating neurobiological and psychoanalytical dimensions of a variety of psychiatric disorders remain far from each other. In his review, Willick summarized recent advances, in that period, in neurobiological research which appeared to offer compelling evidence that the most pathognomonic feature of schizophrenia, the deficit or negative syndrome, might be associated with functional abnormalities in the frontal lobe of the brain which were correlated with those conceptualized by psychoanalytic theories of withdrawal of libido and loss of mental representation. ${ }^{25}$

Regarding OCD, no investigation has attempted to evaluate this relationship. In a brief report, Albucher et al. ${ }^{26}$ investigated the changes in defense mechanisms with the Defense Style Questionnaire after treatment of patients with OCD and found that after behavioral therapy the patients demonstrated significant decreases in Yale-Brown Obsessive Compulsive Scale scores and significant increases in the use of more adaptive defense mechanisms without changes maladaptive defense mechanism categories and concluded that personality as defined by defense mechanisms might be more amenable to brief behavioral treatment than previously thought. On the other hand, Katz proposed a model of 5-HT function involving the routine filtering and suppression of violent or libidinal impulses which appeared to resemble Freud's model of ego-id interactions at least in part, suggesting that it might be possible to psychobiologically substantiate a Freudian metaphor. ${ }^{27} \mathrm{An}$ other effort came from Cath et al. ${ }^{28}$ who undertook to compare measures of psychopathology, personality and blood serotonin between Gillette de la Tourette syndrome (GTS) and OCD (without tics) and evaluated fifteen GTS without OCD subjects, 21 tic with (+) OCD subjects, 15 OCD without tic subjects and 26 controls (all without serotonergic medication) in regard to self-rated and clinician-rated measures of psychopathology and personality and reported that there were interaction effects on platelet MAO, 5-HT, Yale-Brown ObsessiveCompulsive Rating Scale severity, trait anxiety and Eysenck
Personality Questionnaire neuroticism scores. In fact, the approaches existing an integration between psychoanalytical theory and neuroscience are based on Freud's opnion who he sought a unitary conception of mind and brain. ${ }^{26}$ In association with this, relatively increasing interest led some researchers to investigate the association between neurobiological mechanisms and psychodynamic processes. In one of this attemt, Schore et al. ${ }^{7.8}$ propose neurobiological mechanisms of psychodynamic processes, emphazising the developmental features of the right OFC. On the other hand, Northoff et al. ${ }^{20}$ were able to link sensorimotor regression, to a complex neural network including the OFC, medial prefrontal and premotor cortexes. Moreover, Solms ${ }^{6}$ and Solms et al. ${ }^{30}$ make inferences about the localization of early, immature and somatic defense mechanisms, based on psychoanalytic treatment in patients with orbitofrontal cortical lesions. Because of the fact that the OFC plays an important role in both emotion and cognitive interaction, Westen and Gabbard ${ }^{13,14}$ consider this region to be crucial in conflict and compromise. However, despite these attempts and importance of defense mechanisms in psychoanalytic theory and practice, their underlying neuronal mechanisms remain unclear.

Although the importance of OFC is emphasized both in the pathogenesis of OCD and in the neurobiological mecahisms based on psychodynamic process, no study have evaluated its relation to the traditional psychodynamic perspective. In the present study, we aimed to evaluate the relationship between the defense styles consisting of mature, immature and neurotic defenses and OFC volumes in the patients with OCD and thus, to take first step the interaction between psychodynamic and neuroanatomical dimensions of the disorder.

\section{METHODS}

\section{Subjects and clinical evaluation}

Subjects and clinical evaluation design were exactly same as our previous study ${ }^{23}$ which were composed of two age and sex matched groups: OCD and healthy subjects, each had 30 subjects, who were all right handed. The Diagnostic and Statistical Manual of Mental Disorders Fourth Version (DSM-IV) diagnoses were obtained using Turkish version of Structured Clinical Interview for DSM-IV (SCID). ${ }^{29}$ The patients with OCD were selected among the patients who had been recruited from Firat University School of Medicine Department of Psychiatry and had been invited to obtain their magnetic resonance imagings for our aforementioned study in which $30 \mathrm{pa}-$ tients had been included to adjust age and gender. Among these 30 patients, by age and sex adjustment, 24 patients were called by telephone and 18 accepted this. Only two of them were refractory patients while the others were treatment-re- 
sponded ( $n=9)$ and drug-naive ones $(n=7)$. Same number of comparison volunteers were selected among healthy persons who had been recruited from the hospital staff and had been invited to obtain their magnetic resonance imagings for our study aforementioned. Among these 30 controls, by age and sex adjustment, 18 were called and all accepted this. This study was carried out under guidelines of Helsinki Declaration. Written informed consent was obtained from all subjects.

As mentioned in our previous investigation, ${ }^{23}$ the exclusion criteria include the presence of any current or history of comorbid psychiatric disorder, current medical problems, or alcohol/substance abuse within the 6 months preceding the study. Healthy control subjects had no DSM-IV Axis I disorders in self or in a first-degree relative, as determined by the SCID non-patient version, no current medical problems, neurologic or psychiatric histories, and no use of psychoactive medication within 2 weeks of the study.

Of the patients, only four had any Axis II disorder (obsessive compulsive personality disorder in two patients, dependent in one and avoidant in one). As for the controls, none had any Axis I and II disorders. The severity of OCD, used defense styles were evaluated by using the Yale-Brown Obsession Compulsion Scale (Y-BOCS) and Defense Style Questionnaire (DSQ)-40, respectively. ${ }^{30,31}$ Defense mechanisms were divided into three groups by their psychoanalitical function: mature, neurotic and immature styles. The DSQ- 40 are scored by obtaining the average of the two items for each scale. The factor scores are the average of the scale scores for scales 1-4 (mature), scales 5-8 (neurotic), and scales 9-20 (immature defenses). Mature defense styles are sublimation, humor, anticipation, and suppression. Neurotic defense styles include undoing, pseudoaltruism, idealization and reaction-formation whereas immature styles consist of projection, passive-aggression, acting out, isolation, devaluation, autistic fantasy, denial, displacement, dissociation, splitting, rationalization and somatization.

\section{MRI procedure}

As mentioned in our previous study, ${ }^{23}$ magnetic resonance imaging scans were acquired with a $1.5 \mathrm{~T}$ General Electric scanner. Spiral pulse sequences were employed because of insensitivity to subject motion. MRI was obtained on a 1.5-Tesla GE signa Excite high speed scanner (Milwaukee, USA). Spiral pulse sequences were employed because of insensitivity to subject motion. A high-resolution structural image of the entire brain was obtained using sagittally acquired 3D spiral fast spin echo high-resolution images [repetition time $(\mathrm{TR})=2,000$ $\mathrm{ms}$, echo time $(\mathrm{TE})=15.6 \mathrm{~ms}$, field of view $(\mathrm{FOV})=240 \mathrm{~mm}$, flip angle $=20^{\circ}$, bandwidth $=20.8$, slice thickness $=2.4 \mathrm{~mm}$, echo spacing $=15.6 \mathrm{~ms}, 8$ echoes, resolution $=0.9375 \times 0.9375 \times 1.328$ $\mathrm{mm}$. The boundaries of structures evaluated were delineated on the coronal MR images according to standard brain atlas$\mathrm{es}^{32-34}$ and were adapted from Noga et al., ${ }^{35}$ Portas et al., ${ }^{36} \mathrm{Lac}-$ erda et al., ${ }^{37}$ Sassi et al. ${ }^{38}$ and Riffkin et al. ${ }^{39}$ For the tracing procedure for measuring the OFC, superior boundary was defined by a line extending from the anterior commissure to the posterior commissure. On the coronally, the posterior boundary was defined as the point when the olfactory sulcus was first noticed. The inferior boundary was accepted as the most inferior aspect of the cortex. The lateral and medial boundaries were defined as the most lateral edge of the cortex and the medial boundary of each hemisphere by the longitudinal fissure, respectively. Examples of the structures of OFC are presented in Figure 1. All volumes were reported in cubic centimeters. The test-retest relaiblity for tracing was $\mathrm{r}=0.92$ for OFC.

\section{Statistical analysis}

Statistical analyses were conducted using SPSS for Windows software, version 13.0 (SPSS, Chicago, IL). Group differences in demographic variables involving continuous data were computed using independent $\mathrm{t}$-test. Between-group comparisons involving categorical data were assessed using Chi-square test. Correlations were assessed with Spearman's correlation test.

\section{RESULTS}

There was no significant difference between the patients
Figure 1. Anatomic landmarks for the tracing of the OFC. OFC: orbito-frontal cortex.
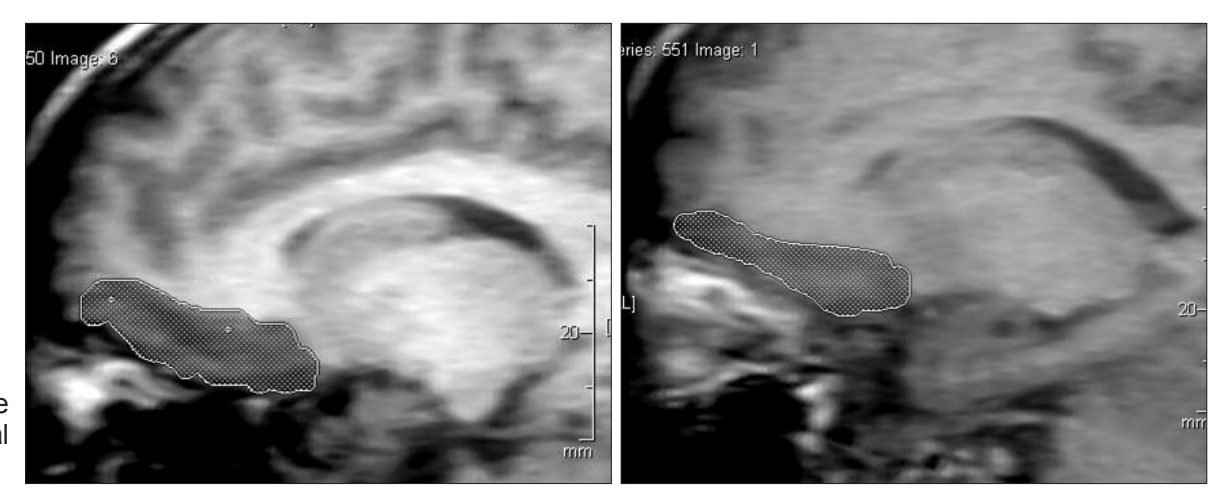
with OCD and healthy controls in age (mean age $\pm \mathrm{SD}=27.7$ \pm 5.1 vs. $28.7 \pm 3.9$ years, respectively; $p>0.05$ ) or gender ( $p>$ 0.05).

Table 1 presents the unadjusted mean volumes of measured structures for the patients and healthy controls. We did not find any significant difference between the OCD patients and healthy controls on ICV $(\mathrm{t}=0.089, \mathrm{df}=34, \mathrm{p}>0.05)$, and total gray matter volumes $(\mathrm{t}=0.69, \mathrm{df}=34, \mathrm{p}>0.05)$, but there was significant greater total white matter volumes in the patients $(t=2.16, d f=34, p=0.038)$. Both sides of the OFC volumes of

Table 1. Clinical and demographic characteristics of normal control subjects and patients with OCD

\begin{tabular}{|c|c|c|}
\hline & $\begin{array}{l}\text { Patients with OCD } \\
\qquad(\mathrm{N}=18)\end{array}$ & $\begin{array}{l}\text { Controls } \\
(\mathrm{N}=18)\end{array}$ \\
\hline Age & $27.7 \pm 5.1$ & $28.7 \pm 3.9$ \\
\hline Gender (F/M) & $11 / 7$ & $11 / 7$ \\
\hline Age at onset (years) & $23.1 \pm 3.7$ & - \\
\hline $\begin{array}{l}\text { Graduated from high } \\
\text { school } 11\end{array}$ & & 15 \\
\hline Handedness (right) & 18 & 18 \\
\hline $\begin{array}{l}\text { Number of subjects who } \\
\text { had family history }\end{array}$ & 3 & 2 \\
\hline \multicolumn{3}{|l|}{ Marital status } \\
\hline Married & 13 & 12 \\
\hline Single & 4 & 6 \\
\hline Divorced & 1 & - \\
\hline \multicolumn{3}{|l|}{ Profession } \\
\hline Housewife & 3 & - \\
\hline Official & 6 & 7 \\
\hline Worker & 6 & 8 \\
\hline Student & 2 & - \\
\hline Others & 1 & 3 \\
\hline \multicolumn{3}{|l|}{ Socioeconomical status } \\
\hline Good & 5 & 7 \\
\hline Medium & 6 & 6 \\
\hline Low & 7 & 5 \\
\hline Y-BOCS score & $22.1 \pm 5.4$ & $5.7 \pm 2.5^{*}$ \\
\hline \multicolumn{3}{|l|}{ DSQ scores } \\
\hline Mature & $30.00 \pm 9.29$ & $41.28 \pm 12.54$ \\
\hline Neurotic & $49.00 \pm 13.99$ & $36.06 \pm 6.86$ \\
\hline Immature & $116.00 \pm 26.92$ & $78.67 \pm 17.38$ \\
\hline \multicolumn{3}{|l|}{ OFC Volume $\left(\mathrm{cm}^{3}\right)$} \\
\hline Left & $12.71 \pm 0.91$ & $14.62 \pm 1.25^{*}$ \\
\hline Right & $11.80 \pm 1.12$ & $13.71 \pm 1.42^{*}$ \\
\hline
\end{tabular}

No significant differences exist between groups in age, handedness, education, and gender composition. ${ }^{*} \mathrm{p}<0.001$. Y-BOCS: Yale Brown obsession compulsion scale, DSQ: defense style questionnaire, OFC: orbito-frontal cortex, OCD: obsessive compulsive disorder the patients were significantly smaller than those of healthy controls $(\mathrm{t}=-5.084, \mathrm{df}=34, \mathrm{p}<0.001$ for right $\mathrm{OFC}$ and $\mathrm{t}=-5.415$, $\mathrm{df}=34, \mathrm{p}<0.001$ for left OFC) even after covarying for ICV and Y-BOCS scores $(\mathrm{F}=4.88, \mathrm{p}<0.05$ for age, and $\mathrm{F}=4.12, \mathrm{p}<0.05$ for Y-BOCS).

As expected, scores of mature factor were 30.00 \pm 9.29 for patients and $41.28 \pm 12.54$ for control subjects, respectively $(\mathrm{t}=$ $-3.065, \mathrm{df}=34, \mathrm{p}=0.004)$. The scores of the neurotic factor were significantly higher in patient group compared to healthy comparisons [ $49.00 \pm 13.99$ for patients and $36.06 \pm 6.86$ for control subjects, respectively $(\mathrm{t}=3.524, \mathrm{df}=34, \mathrm{p}=0.001)]$. In regard to scores of immature factor, these scores were also statistically significant higher in patients $(116.00 \pm 26.92)$ compared to control subjects $(78.67 \pm 17.38)(\mathrm{t}=4.943, \mathrm{df}=34, \mathrm{p}<0.001)$. No gender-related defense style difference was found in both patient and control groups for any style ( $\mathrm{p}>0.05)$.

No significant relationship was found between the right OFC volumes of the patient group and their scores of mature (Spearman's rho $=0.176, \mathrm{p}>0.05$ ), neurotic (Spearman's rho $=-$ $0.341, \mathrm{p}>0.05$ ), or immature defense mechanism scores ( $\mathrm{Sp}-$ earman's rho $=-0.191, \mathrm{p}>0.05)$. As for the left OFC volumes, there was statistically significant association with the scores of immature defense mechanisms (Spearman's rho $=0.653, \mathrm{p}=$ 0.003 )(Figure 2). However, no association was found between the left OFC volumes and the scores of neurotic or matures defense styles (Spearman's rho $=0.130, \mathrm{p}>0.05$ for the neurotic defense styles and Spearman's rho=-0.053, p >0.05 for the mature defense styles). For the healthy comparison group, no relationship was found between the right and left OFC volumes and the scores of any defense styles (Spearman's rho=-0.259, p $>0.05$ for the right OFC-mature styles; Spearman's rho=

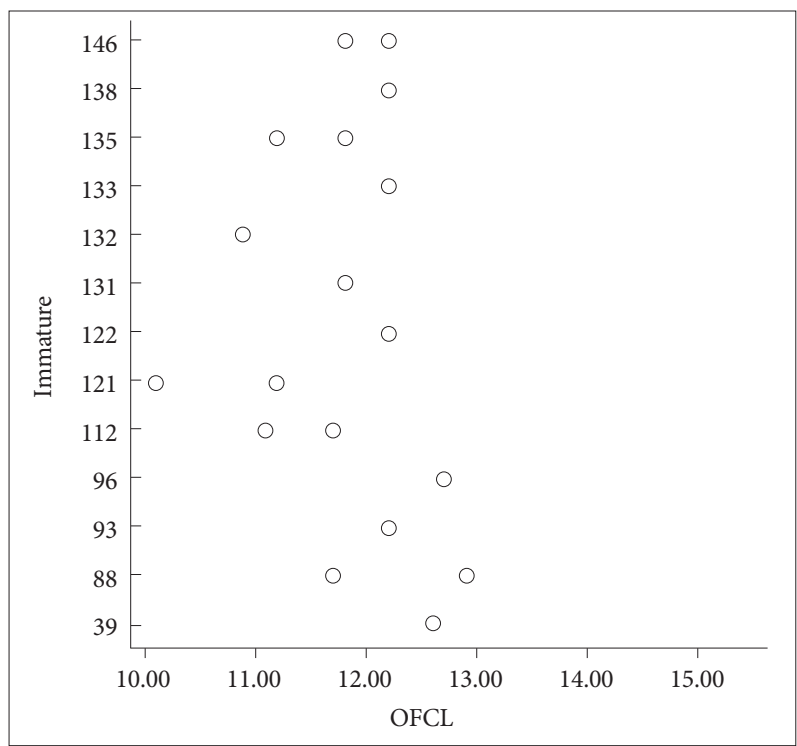

Figure 2. Correlation between immature defenses and left OFC volumes. OFC: orbito-frontal cortex, OFCL: orbito-frontal cortex-left. 
$-0.311, \mathrm{p}>0.05$ for the right OFC-neurotic styles; Spearman's rho $=-0.150, p>0.05$ for the right OFC-immature styles; Spearman's rho $=-0.140, p>0.05$ for the left OFC-mature styles; Spearman's rho $=0.089, \mathrm{p}>0.05$ for the left OFC-neurotic styles; and Spearman's rho $=0.238, \mathrm{p}>0.05$ for the left OFC-immature styles).

\section{DISCUSSION}

To our knowledge, this is the first study which consists of brain volumetric variables and psychoanalitical data in OCD. Beyond finding greater volumes of total white matter and smaller OFC volumes as determined previously by our group, ${ }^{24}$ the main findings of the present study were us to find no significant relationship between the right OFC volumes of the patient group and their scores of mature, neurotic, or immature defense mechanism scores, but as for the left OFC volumes, to detect a significant relation with the scores of immature defense mechanisms (Spearman's rho $=0.653, \mathrm{p}=0.003$ ) while no association was found about the scores of neurotic or mature defense styles.

This area is considerably novel even in all kinds of psychiatric disorders including schizophrenia and depression on which there are so many studies compared to OCD. In addition to our important findings aforementioned, another important finding was that the scores of mature defense styles were lower in the patients with OCD compared to healthy controls, while those of neurotic and immature styles were significantly higher in the patient group than healthy comparisons. Our this finding that the scores of mature defense styles were lower in the patients with OCD compared to healthy controls, while those of neurotic and immature styles were significantly higher in the patint group than healthy comparisons was actually expected one. Actually, this is an expected finding which has been supported by Albucher et al. ${ }^{26}$ found that after behavior therapy the patients demonstrated a significant decreases in Y-BOCS scores and significant increases in the use of more adaptive defense mechanisms without any significant changes in maladaptive defense mechanism categories.

The second and main finding of the present study was that no significant relationship was found between the right OFC volumes of the patient group and their scores of mature, neurotic, or immature defense mechanism scores, but as for the left OFC volumes, a significant relation was determined with the scores of immature defense mechanisms while no association was detected about the scores of neurotic or matures defense styles. In our unpublished study, ${ }^{40}$ we examined the relationship between the defense styles and $\mathrm{NAA}, \mathrm{CHO}$, and CRE values in hippocampal regions of OCD patients and found important correlations. As can be extracted from our another study, defense styles seem to be associated with neurochemical variables. However, one of the most important regions in the pathophysiology of OCD, OFC's volumetric data do not seem to be related to the defense styles, except a significant relation with the scores of immature defense mechanisms for the left OFC.

The meaning of the finding that there was no relationship between OFC volumes and neurotic defense styles but was a relationship between the immature defense styles and left OFC volumes but not right is unclear and needed further exploration. Several explanations may be done for this. Firstly, we should accept the fact that positive results may be artefact. Secondly, in our previous study, ${ }^{23}$ we found that first applying patients had significantly smaller left and right OFC volumes compared with treatment-responded patients and healthy controls, with a significant difference between refractory patients and treatment-responded patients for both sides and no significant difference between the volume of first applying patients compared to that of refractory patients. In that study, we suggested that reductions in OFC and increase in thalamic volumes might be associated with refractoriness of $\mathrm{OCD}$ and might not be due to changes in cingulate and caudate regions. This led us to consider that refractoriness to treatment might be associated with more use of immature defense mechanisms rather than neurotic ones. As for the issue of side, in that study, ${ }^{23}$ by using analysis of covariance controlling for age and intracranial volume, the reduction in left OFC was more obvious compared to right side despite for both sides there were significant difference compared to -responded patients and healthy controls. This difference may explain our finding found in the present study that there was statistically significant association with the scores of immature defense mechanisms.

Some factors need to be considered when interpreting these results. First, the relatively small and homogeneous sample may limit the generalizability of our findings to OCD. It requires the replication with larger samples whether our findings are applicable to cases of patients with OCD with psychotic features. Second, as we acknowledged, the statistical threshold applied is somewhat liberal, further underscoring the need for replication. Third, single but important key brain region for OCD, OFC was investigated in this study. Finally, whereas the current investigation utilized a retrospective design in part, a prospective research design is ultimately necessary.

In conclusion, the results of the present study indicate being no significant relationship between OFC volumes of the patient group and their scores of mature, neurotic, or immature defense mechanism scores, except a significant relation with the scores of immature defense mechanisms and lead us to consider defense styles seem to be associated with neuro- 
chemical variables in OCD, taking into consideration our unpublished study.

\section{REFERENCES}

1. Stein DJ, Goodman WK, Rauch SL. The cognitive-affective neuroscience of obsessive-compulsive disorder. Curr Psychiatry Rep 2000;2: 341-346.

2. Insel TR. Toward a neuroanatomy of obsessive-compulsive disorder. Arch Gen Psychiatry 1992;49:739-744.

3. Scarone S, Colombo C, Livian S, Abbruzzese M, Ronchi P, Locatelli M, et al. Increased right caudate nucleus size in obsessive-compulsive disorder: detection with magnetic resonance imaging. Psychiatry Res 1992; 45:115-121.

4. Robinson D, Wu H, Munne RA, Ashtari M, Alvir JM, Lerner G, et al. Reduced caudate nucleus volume in obsessive-compulsive disorder. Arch Gen Psychiatry 1995;52:393-398.

5. Szeszko PR, Robinson D, Alvir JM, Bilder RM, Lencz T, Ashtari M, et a1. Orbital frontal and amygdala volume reductions in obsessive-compulsive disorder. Arch Gen Psychiatry 1999;56:913-919.

6. Jenike MA, Breiter HC, Baer L, Kennedy DN, Savage CR, Olivares MJ, et al. Cerebral structural abnormalities in obsessive-compulsive disorder. A quantitative morphometric magnetic resonance imaging study. Arch Gen Psychiatry 1996;53:625-632.

7. O'Sullivan RL, Rauch SL, Breiter HC, Grache ID, Baer L, Kennedy DN, et al. Reduced basal ganglia volumes in trichotillomania measured via morphometric magnetic resonance imaging. Biol Psychiatry 1997;42: $39-45$.

8. Rosenberg DR, Benazon NR, Gilbert A, Sullivan A, Moore GJ. Thalamic volume in pediatric obsessive-compulsive disorder patients before and after cognitive behavioral therapy. Biol Psychiatry 2000;48:294-300.

9. Bartha R, Stein MB, Williamson PC, Drost DJ, Neufeld RW, Carr TJ, et al. A short echo $1 \mathrm{H}$ spectroscopy and volumetric MRI study of the corpus striatum in patients with obsessive-compulsive disorder and comparison subjects. Am J Psychiatry 1998;155:1584-1591.

10. Riffkin J, Yücel M, Maruff P, Wood S.J, Soulsby B, Olver J, et al. A manual and automated MRI study of anterior cingulate and orbito-frontal cortices, and caudate nucleus in obsessive-compulsive disorder: comparison with healthy controls and patients with schizophrenia. Psychiatry Res 2005;138:99-113.

11. Pujol J, Soriano-Mas C, Alonso P, Cardoner N, Menchón JM, Deus J, et al. Mapping structural brain alterations in obsessive-compulsive disorder. Arch Gen Psychiatry 2004;61:720-730.

12. Choi JS, Kang DH, Kim JJ, Ha TH, Lee JM, Youn T, et al. Left anterior subregion of orbitofrontal cortex volume reduction and impaired organizational strategies in obsessive-compulsive disorder. J Psychiatr Res 2004;38:193-199.

13. Whiteside SP, Port JD, Abramowitz JS. A meta-analysis of functional neuroimaging in obsessive-compulsive disorder. Psychiatry Res 2004; 132:69-79.

14. Rauch SL, Savage CR. Neuroimaging and neuropsychology of the striatum. Bridging basic science and clinical practice. Psychiatr Clin North Am 1997;20:741-768.

15. Macmaster F, Vora A, Easter P, Rix C, Rosenberg D. Orbital frontal cortex in treatment-naïve pediatric obsessive-compulsive disorder. Psychiatry Res 2010;181:97-100.

16. Zald DH, Kim SW. Anatomy and function of the orbital frontal cortex, I: anatomy, neurocircuitry; and obsessive-compulsive disorder. J Neuropsychiatry Clin Neurosci 1996;8:125-138.

17. Gilbert AR, Moore GJ, Keshavan MS, Paulson LA, Narula V, MacMaster FP, et al. Decrease in thalamic volumes of pediatric patients with obsessive-compulsive disorder who are taking paroxetine. Arch Gen Psychiatry 2000;57:449-456.

18. Smith EA, Russell A, Lorch E, Banerjee SP, Rose M, Ivey J, et al. Increased medial thalamic choline found in pediatric patients with obsessive-compulsive disorder versus major depression or healthy control subjects: a magnetic resonance spectroscopy study. Biol Psychiatry 2003;54:13991405.

19. Szeszko PR, MacMillan S, McMeniman M, Lorch E, Madden R, Ivey J, et al. Amygdala volume reductions in pediatric patients with obsessivecompulsive disorder treated with paroxetine: preliminary findings. Neuropsychopharmacology 2004;29:826-832.

20. Mirza Y, O’Neill J, Smith EA, Russell A, Smith JM, Banerjee SP, et al. Increased medial thalamic creatine-phosphocreatine found by proton magnetic resonance spectroscopy in children with obsessive-compulsive disorder versus major depression and healthy controls. J Child Neurol 2006;21:106-111.

21. Zald DH, Kim SW. Anatomy and function of the orbital frontal cortex, II: Function and relevance to obsessive-compulsive disorder. J Neuropsychiatry Clin Neurosci 1996;8:249-261.

22. Kringelbach ML. The human orbitofrontal cortex: linking reward to hedonic experience. Nat Rev Neurosci 2005;6:691-702.

23. Atmaca M, Yildirim BH, Ozdemir BH, Aydin BA, Tezcan AE, Ozler AS. Volumetric MRI assessment of brain regions in patients with refractory obsessive-compulsive disorder. Prog Neuropsychopharmacol Biol Psychiatry 2006;30:1051-1057.

24. Atmaca M, Yildirim H, Ozdemir H, Tezcan E, Poyraz AK. Volumetric MRI study of key brain regions implicated in obsessive-compulsive disorder. Prog Neuropsychopharmacol Biol Psychiatry 2007;31:46-52.

25. Willick MS. The deficit syndrome in schizophrenia: psychoanalytic and neurobiological perspectives. J Am Psychoanal Assoc 1993;41:11351157.

26. Albucher RC, Abelson JL, Nesse RM. Defense mechanism changes in successfully treated patients with obsessive-compulsive disorder. Am J Psychiatry 1998;155:558-559.

27. Katz RJ. Neurobiology of obsessive compulsive disorde--a serotonergic basis of Freudian repression. Neurosci Biobehav Rev 1991;15:375-381.

28. Cath DC, Spinhoven P, Landman AD, van Kempen GM. Psychopathology and personality characteristics in relation to blood serotonin in Tourette's syndrome and obsessive-compulsive disorder. J Psychopharmacol 2001;15:111-119.

29. Çorapcioglu A, Aydemir Ö, Yıldız M, Esen Danaci A, Köroglu E. DSMIV Eksen I Bozuklukları (SCID-I) İçin Yapılandırılmış Klinik Görüşme, Klinik Versiyon. Hekimler Yayın Birliği; 1999.

30. Watson DC, Sinha BK. Gender, age, and cultural differences in the Defense Style Questionnaire-40. J Clin Psychol 1998;54:67-75.

31. Yilmaz N, Gençöz T, Ak M. [Psychometric properties of the defense style questionnaire: a reliability and validity study]. Turk Psikiyatri Derg 2007;18:244-253.

32. Yuh WTC, Tah ET, Afifi AK, Sahinoglu K, Gao F, Bergman RA. MRI of Head and Neck Anatomy, New York: Churchill Livingstone; 1994.

33. Jackson GD, Duncan JS. MRI Anatomy. A New Angle on the Brain. New York: Churchill Livingstone; 1996.

34. Patel VH, Friedman L. MRI of the Brain: Normal Anatomy and Normal Variants. Philadelphia: WB Saunders Company; 1997.

35. Noga JT, Aylward E, Barta PE, Pearlson GD. Cingulate gyrus in schizophrenic patients and normal volunteers. Psychiatry Res 1995;61:201208.

36. Portas CM, Goldstein JM, Shenton ME, Hokama HH, Wible CG, Fischer I, et al. Volumetric evaluation of the thalamus in schizophrenic male patients using magnetic resonance imaging. Biol Psychiatry 1998;43: 649-659.

37. Lacerda AL, Nicoletti MA, Brambilla P, Sassi RB, Mallinger AG, Frank E, et al. Anatomical MRI study of basal ganglia in major depressive disorder. Psychiatry Res 2003;124:129-140.

38. Sassi RB, Brambilla P, Hatch JP, Nicoletti MA, Mallinger AG, Frank E, et al. Reduced left anterior cingulate volumes in untreated bipolar patients. Biol Psychiatry 2004;56:467-475.

39. Riffkin J, Yücel M, Maruff P, Wood SJ, Soulsby B, Olver J, et al. A manual 
and automated MRI study of anterior cingulate and orbito-frontal cortices, and caudate nucleus in obsessive-compulsive disorder: comparison with healthy controls and patients with schizophrenia. Psychiatry Res 2005;138:99-113.
40. Atmaca M, Özdemir H, Koç M, Korkmaz S, Özler S, Erenkuş Z. Relationship between defense styles and neurochemical variables of hippocampus in patients with obsessive-compulsive disorder (unpublished study). 